\title{
The Crack Analysis of Fatigue Tested Steel Construction
}

Zbynek Bunda, Ludmila Kucerova, Miloslav Kepka

Regional Technological Institute, University of West Bohemia. Univerzitni 8, 30614 Pilsen. Czech Republic. E-mail: bunda@rti.zcu.cz, skal@rti.zcu.cz,kepkami1@rti.zcu.cz

Laboratory fatigue testing is an important part of the fatigue design of machine components that are supposed to work under cyclic loading. These tests are used to confirm whether the tested component matches the required fatigue life and they also serve as a verification of the numerical calculations. This paper describes a fatigue life testing of a welded steel construction. The testing was carried out in the Regional Technological Institute (RTI) using an electro-hydraulic loading system, which allows realization of the tests simulating a real service. An integral part of the fatigue tests is a pre-scheduled inspection of the crack initiation and propagation. The tested construction was checked using non-destructive magnetic particle testing before the fatigue test and also during and after the performed test. Some cracks were observed, especially in the weld area. The biggest crack had the length of approximately $40 \mathrm{~cm}$. This crack was cut out and underwent detailed metallographic and fractographic analysis to estimate the effect of material purity and quality of the weld on the fracture.

Keywords: Fatigue, Magnetic Particle Testing, Fractography

\section{Introduction}

The aim of this contribution is to present crack analysis of a welded frame for agriculture machinery during fatigue life testing of the component. Magnetic particle testing (MT) is a useful technique, typically used to detect surface cracks in ferromagnetic materials. In MT, the yoke method is mainly applied because of its easy operation. In the case when the fracture is detected, metallographic and fractographic analysis could be applied to investigate the cause of early fracture imitation and propagation. The main reasons for the fracture could be unsuitable geometry with regard to applied stresses, low metallurgical purity of used material or technological problems with either heat treatment or welding. The quality of the surface and stress distribution in the surface layers of the material are particularly important for parts loaded by fatigue.

\section{Static and fatigue testing}

Before the frame is put into service, it is tested in a laboratory in static and fatigue tests. The test loads correspond to the loading states employed for computational stress analysis. Static testing involves stress measurement in selected locations of the frame and checking the readings against the values calculated by computational stress analysis. The main limitation to the fatigue life of a frame is the presence of welds. All weld joints in the tested frame are classified into notch categories with respect to the stress ratio $\mathrm{R}$. These values are calculated for all loading condition. [1]

The laboratory of service strength of Regional Technological Institute (RTI) is equipped with the universal electrohydraulic loading system for dynamic testing of structures and material samples. The major equipment of the laboratory consists of independent loading, four horizontal brackets and the vertical two column frame with an adjustable-height crosshead, that are mounted on a T-slotted plate. The cylinders can be set into variable configurations and the configuration of the testing stand can be seen on Fig 1.

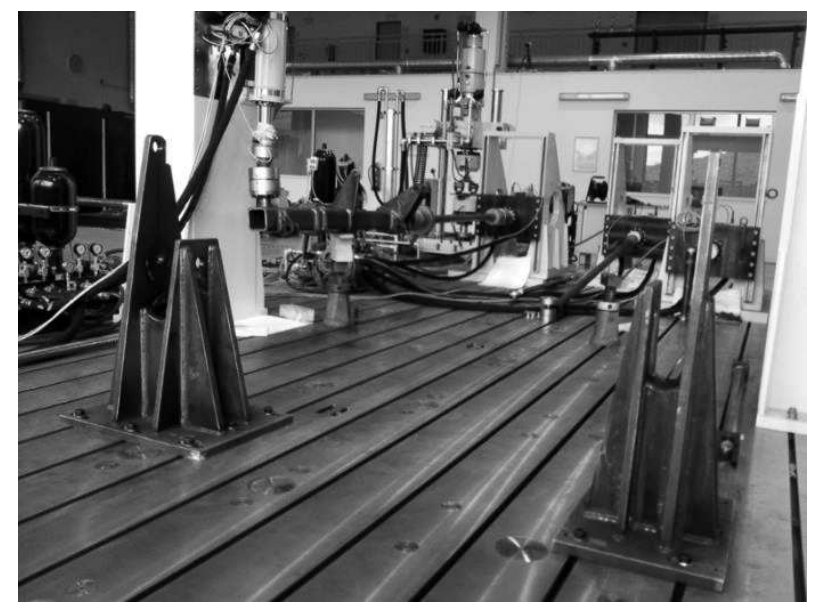

Fig. 1 The laboratory prepared for testing of the frame

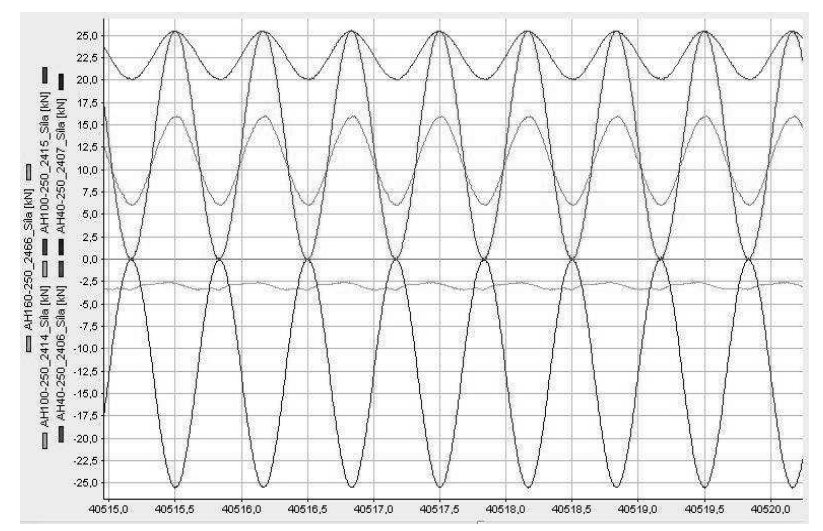

Fig. 2 The loading in software TestControl

The testing stand was prepared to simulate the loading conditions of the frame in work and also loading during transport. The loading was programmed and controlled by the software TestControl developed by INOVA company. Fig. 2 illustrates an example of such a loading. The static and fatigue testing methodology used in RTI was presented in more detail in the literature [2]. 


\section{Non-destructive testing}

Magnetic particle testing is a non-destructive method that detects discontinuities that are either buried slightly below or open to the material or weld surface. Its advantage over visual inspection is that it can detect defects that are buried below the surface as well as surface opening defects that are too small to be visible by the naked eye. The sensitivity of the method is dependent on several factors as described in this chapter.

The process is limited to such materials that have ferromagnetic properties responding to magnetic principles. This implies that this method is not applicable for nonferrous and nonmagnetic material.

Because a wide variety of discontinuities can be located by this method, the training and experience of the tester are of great importance. For example, a person experienced in interpreting castings may not find it easy to interpret defects in welding or wrought material; the same is true for an experienced weld defect interpreter if asked to interpret castings.

The process requires some fundamentals to be correctly identified and agreed to before the testing. These are often written or referenced documents called specifications. They address the following essential points [3].

The frame was checked using non-destructive fluorescent magnetic particle method with UV lamp in accordance to the standards ČSN EN ISO 17638, ČSN EN ISO 9934 - 1. Magnetic yoke Tiede 220 TWM with pole distance $170 \mathrm{~mm}$ and UV lamp Labino was used. The time of magnetization was 10 seconds. The magnetic particle test was done on $100 \%$ surface of the frame, on both sides. The surface was cleaned and degreased before the magnetic particle testing using spray cleaner TIEDE PEN RL-40. There was surrounding light smaller than 15 $1 x$. For the testing was used fluorescent magnetic detecting medium TIEDE FluoFLUX 690.1 as fluorescent magnetic powder.

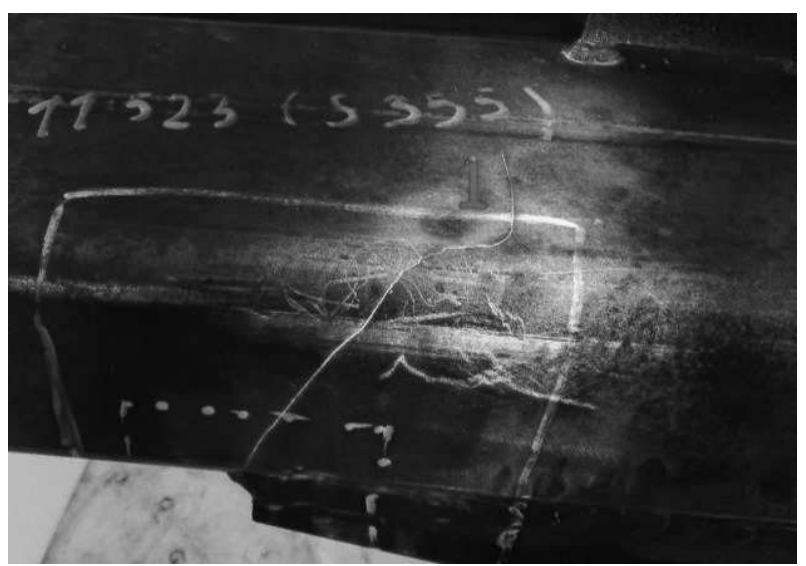

Fig. 3 The longest linear indication after 1200000 cycles

After 1200000 cycles were found 3 indications (Fig. $3,4,5)$. These indications were after MT repaired with weldings. The longest indication was about $40 \mathrm{~cm}$ (Fig 3.). This crack was cut out and fractographic analysis was done. The cutted sample was replaced with a new material. Next magnetic particle test was done after 1500000 . cycles. The last 300000 cycles were performed with increased loading force about $20 \%$. During this test were found 4 linear indications. 2 of them were old and repaired with weldings and 2 were new (Fig. 5, 6).

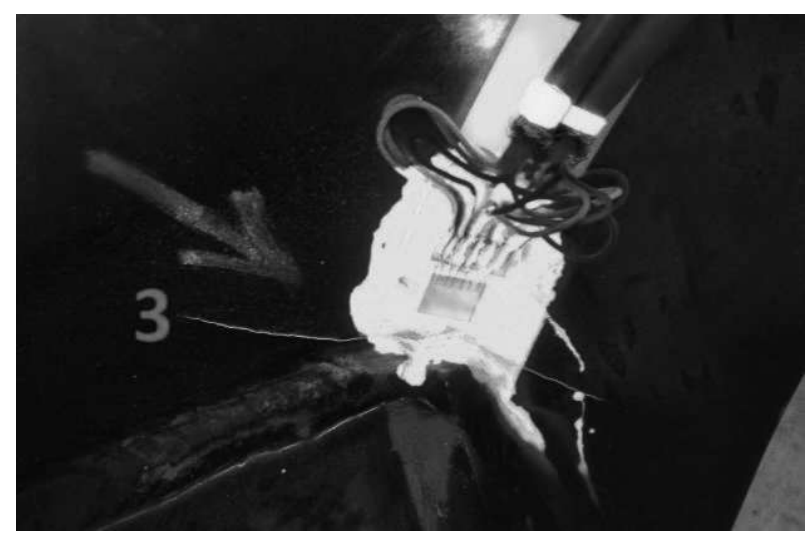

Fig. 4 Detail of the linear indication near the strain gauge after 1200000 cycles

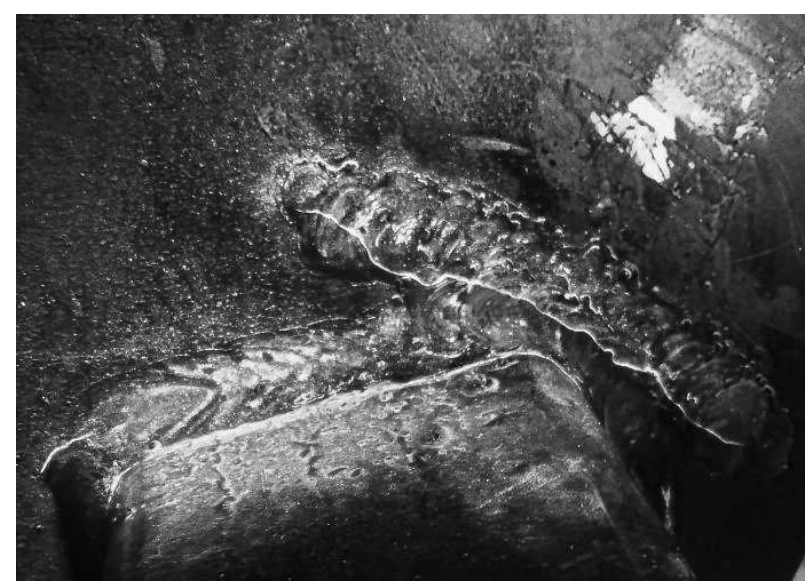

Fig. 5 Detail of the linear indication, repaired after 1200000 cycles, after 1500000 cycles occurrence again in weld

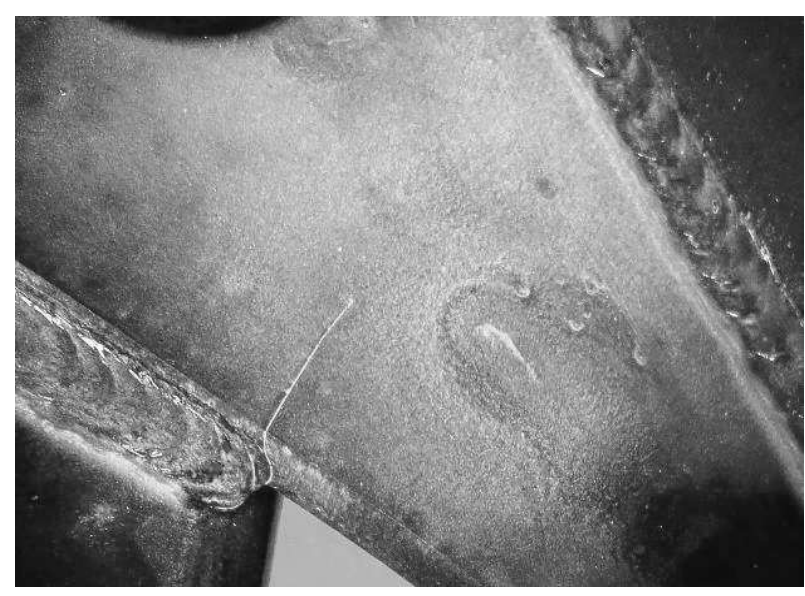

Fig. 6 Detail of the linear indication after 1500000 cycles

\section{Metallography and fractography}

Part of the frame with the crack detected by NDT was cut out for microscopy analysis and fractography. The area with fracture origin was found by observation using 
stereo-microscope and separated for further analysis. After observation of fracture surface, a metallographic cross section was prepared from the plane perpendicular to the fracture surface going through the area of fracture initiation, to reveal the quality of the weld. Detailed fractography and metallographic analysis were carried out at an
EVO 25 scanning electron microscope. Light microscopy was applied to gain the overview of microstructure development of the welded area. Nital etching was used to reveal the microstructure of metallographic sample.
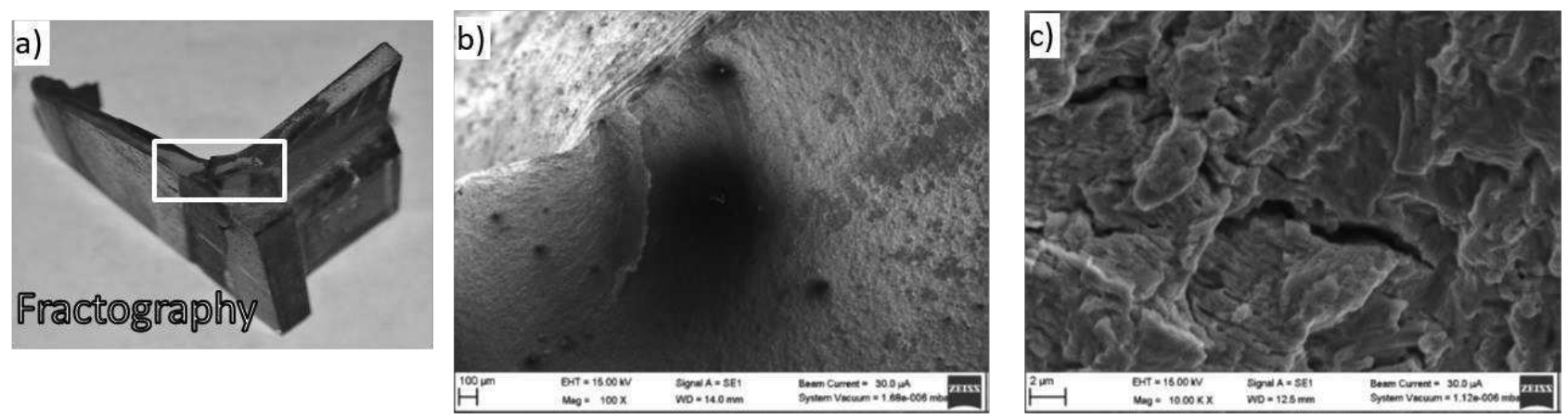

Fig. 7 Part of the crack with failure initiation area cut from the frame, (a) overview of fracture surface with initiation area marked by a white rectangular, $(b)$ detail of the fracture initiation at the surface of the frame, (c) detail of fracture surface with striation created by gradual propagation of a fatigue crack and secondary cracks.

Fracture initiation site was detected at the surface of the welded part and the traces of propagation of fatigue failure were found at fracture surface (Fig.7). The initiation was placed at the interface of weld metal and base material, at the outer surface of bended part of the frame. This is the area with the highest tensile loading during bending. Numerous sulphur inclusions were found in the base material, showing low metallurgical purity of used steel. Relatively large defects were observed also in weld metal (Fig 8) in the proximity of fracture initiation site. Using EDS (Energy-dispersive X-ray spectroscopy) analysis, the presence of oxides was confirmed in the spherical defect (Fig. 8c, e) and also in the defect with a "crank" shape (Fig. 8d). It became also obvious that the joint was not welded completely thought (Fig. 8b). Large numbers of fine oxidic particles with increased amount of $\mathrm{M}$ and Si were also found in heat affected zone in the proximity of the weld-base metal interface. The microstructure of the base material was predominantly ferritic with very small pearlitic areas and it gradually changed to acicular ferrite in heat affected zone. The microstructure of the weld was mainly bainitic with either long columns of bainite or bainitic blocks with ferrite formed at the prior austenite grain boundaries.
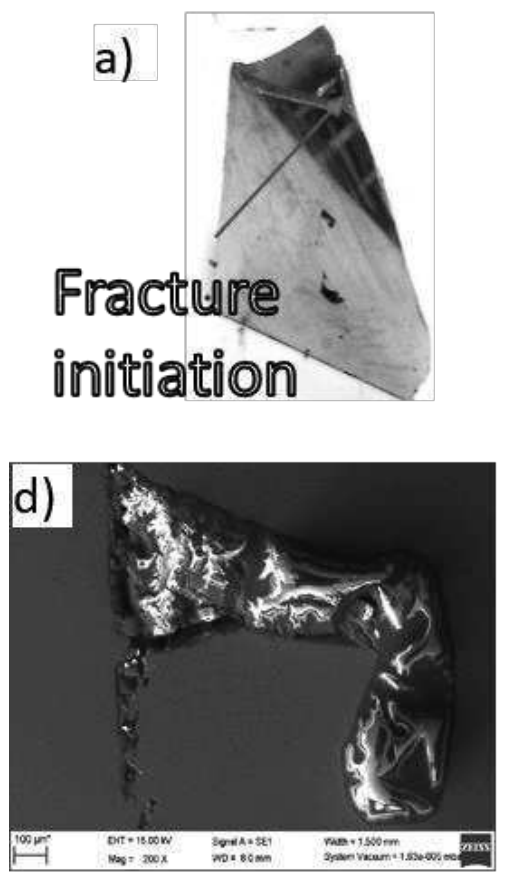
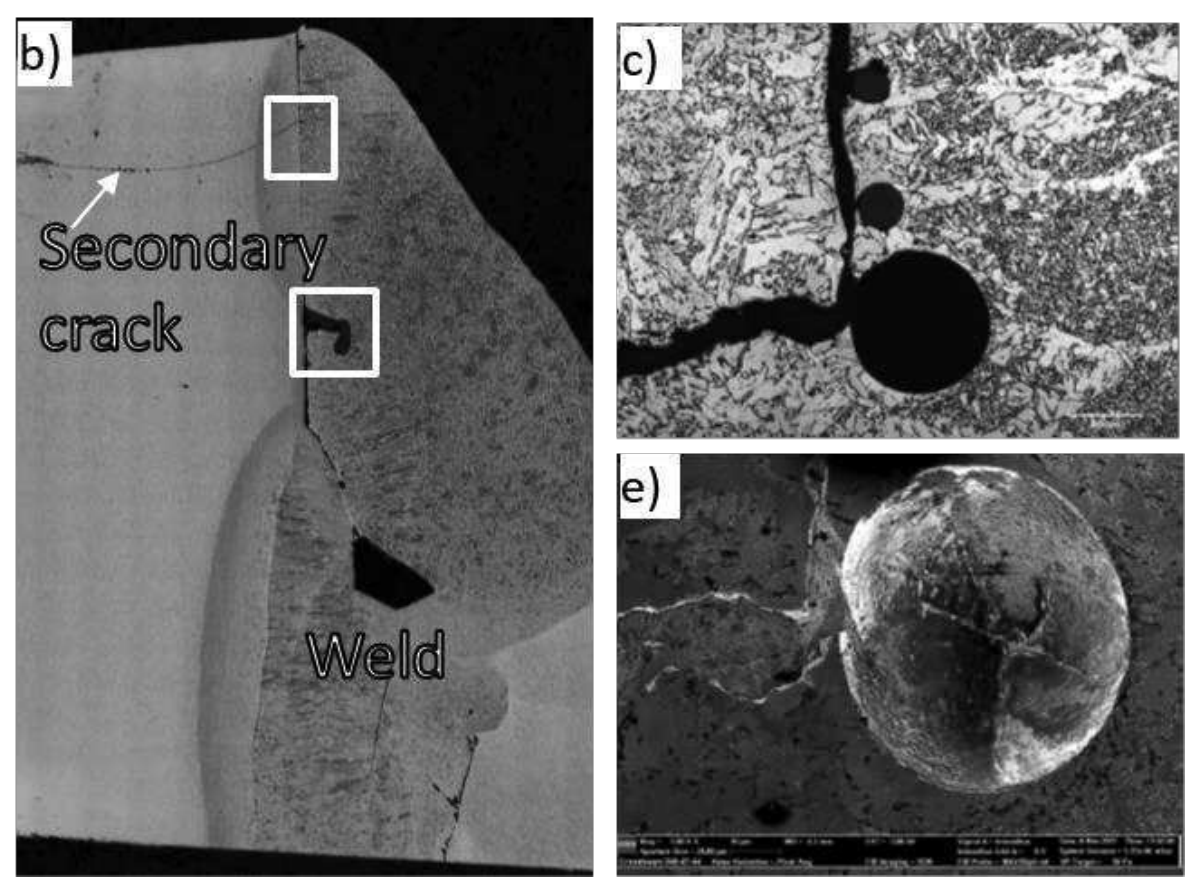

Fig. 8 Metallography of the cross section perpendicular to fracture surface, provided in the area of crack initiation. (a) part of the frame for metallographic analysis, $(b)$ macro of etched cross section, areas of defects found at the weld-base metal interface marked in white rectangulars, (c) detail of the upper defect with initiation of secondary crack from the spherical defect, (d) detail of the "crank" shaped defect, (e) detail of spherical defect from Fig. 7(c). 


\section{Conclusion}

The frame was subjected to the laboratory fatigue testing, where the real service conditions were simulated. After $1,200,000$ cycles the frame was taken under inspection using magnetic particle testing. Three macroscopic fatigue cracks were found in the weld area. The longest fatigue crack was cut off and subjected to fractography and metallography analysis.

Magnetic particle testing method was chosen based on its simplicity and price. Its importance results from the fact that this method is relatively quick, simple, operationally inexpensive and does not break the test material. Fluorescent magnetic yoke and UV lamp were used for detection of indications. Numerous linear indications were found in presented frame using magnetic particle method. The largest crack was then analysed using light and scanning electron microscopy. It was found out that initiation of the fatigue failure was supported by a large amount of defects at the weld-base material interface combined with high tensile stresses in the outer surface of the radius.

Fatigue test supported by NDT and metallography led to the identification and removal of imperfections in design and also in a welding technology.

\section{Acknowledgement}

The present contribution has been prepared under project LO1502 'Development of the Regional Technological Institute' under the auspices of the National Sustainability Programme I of the Ministry of Education of the Czech Republic aimed to support research, experimental development and innovation.

\section{References}

[1] KRAUS, V., KEPKA, M., KEPKA, M., DOUBRAVA, D., CHVOJAN, J. (2018). Strength analysis of tramway bogie frame, 19th International Colloquium on Mechanical Fatigue of Metals 5-7th September 2018, Faculty of Engineering, University of Porto.

[2] KALINA, T., HELLER, P., CHVAL, Z., SEDLÁČEK, F., KRIZEK, M., BARTON, L. (2018). Numerical Simulation and Experimental Testing of Two-axle Chassis of Low-floor Trams. Manufacturing Technology, April 2018, Vol. 18, No. 2.

[3] SINGH, R. (2016). Applied Welding Engineering, Processes, Codes and Standards, pp. 327. Elsevier Inc. 